Check for updates

Cite this: RSC Adv., 2017, 7, 30481

Received 19th April 2017

Accepted 27th May 2017

DOI: $10.1039 / c 7 r a 04394 e$

rsc.li/rsc-advances

\title{
A fluorescence turn-off-on chemosensor based on carbon nanocages for detection of ascorbic acid $\dagger$
}

\begin{abstract}
Jingran $\mathrm{Bi}^{\text {abc }}{ }^{\text {Haitao Wang, }}{ }^{\text {bc }}$ Tariq Kamal, ${ }^{\text {bc }}$ Bei-Wei Zhu*abc and Mingqian Tan (DD *bc
A new type of carbon nanocages (CNCs) has been constructed through grilling of turbot (Scophthalmus maximus L.) by a facile method, and applied successfully as a fluorescent probe for rapid, selective as well as sensitive detection of ascorbic acid (AA). The one-step fabricated CNCs were thoroughly characterized by transmission electron microscopy (TEM), Fourier transform infrared spectroscopy (FTIR) and UV-vis spectroscopy. The CNCs showed very selective and sensitive quenching in the presence of $\mathrm{Fe}^{3+}$. The quenching efficiency of the CNCs was significantly correlated with the concentration of $\mathrm{Fe}^{3+}$ in the range $20-110 \mu \mathrm{M}$. The linear regression equation is $y=0.00868 x-0.0981\left(R^{2}=0.993\right)$ with the detection limit of the $\mathrm{CNCs}$ for $\mathrm{Fe}^{3+}$ at $3.96 \mu \mathrm{M}$. Furthermore, the fluorescence of $\mathrm{CNCs}-\mathrm{Fe}^{3+}$ displayed a turn-on behavior upon adding $\mathrm{AA}$ due to the reduction of $\mathrm{Fe}^{3+}$ to $\mathrm{Fe}^{2+}$. A good linear relationship between the $\mathrm{AA}$ concentration and fluorescence intensity was obtained in the range of 2 to $12 \mu \mathrm{M}\left(R^{2}=\right.$ 0.998 ) with a detection limit of $97.2 \mathrm{nM}$ of AA. The selectivity of the $\mathrm{CNCs}-\mathrm{Fe}^{3+}$ for the detection of $\mathrm{AA}$ was explored in the presence of other possible reducing agents. Only AA induced a significant fluorescence restoration of $\mathrm{CNCs}-\mathrm{Fe}^{3+}$, the signal being approximately 5-fold greater than with other reducing agents (uric acid, dopamine, human serum albumin, D-glucose and hemoglobin). Notably, the developed probe was successfully applied for the quantitative detection of AA in vitamin tablets with recoveries from $99.77 \%$ to $104.76 \%$.
\end{abstract}

\section{Introduction}

Ascorbic acid (AA), known as vitamin C, is widely distributed in nature. It plays a major role in numerous biochemical reactions, including the formation of collagen, amino acid metabolism, immune functions, and non-harmful iron absorption. ${ }^{1}$ In particular, AA acts as a necessary reactant in synthetic and decomposition reactions during hydroxylation processes in organisms. ${ }^{2,3}$ The biological activity of AA has significant implications for human health. Generally, a daily intake of 70-90 mg AA per day is the recommended dose for adults. ${ }^{4}$ Moreover, AA has been employed in supplements and medicines to treat colds, remove toxins and prevent cancer, ${ }^{5}$ where its health benefits are attributed to its primary defensive function of a free-radical scavenger of reactive oxygen and nitrogen species. ${ }^{6}$ Therefore, the detection of AA has received a great deal of attention, and a variety of methods have been developed for AA quantitative

${ }^{a}$ School of Food \& Biological Engineering, Jiangsu University, Zhenjiang 212013, China.E-mail: zhubeiwei@163.com

${ }^{b}$ School of Food Science and Technology, Dalian Polytechnic University, National Engineering Research Center of Seafood, Dalian 116034, China.E-mail: mqtan@ dlpu.edu.cn; Fax: +86-411-86318657; Tel: +86-411-86318657

${ }^{c}$ Engineering Research Center of Seafood of Ministry of Education of China, Dalian 116034, China

$\dagger$ Electronic supplementary information (ESI) available. See DOI: $10.1039 / \mathrm{c} 7 \mathrm{ra} 04394 \mathrm{e}$ determination, including electrochemical methods, ${ }^{7,8}$ highperformance liquid chromatography (HPLC) ${ }^{9,10}$ and flame atomic absorption spectrometry. ${ }^{11,12}$ These methods have shown great success in AA detection.

As an important supplementary technique, "turn-on" sensing fluorescence methods with high sensitivity and operational simplicity have gained considerable attention. ${ }^{13}$ Briefly, the fluorescent probes are in the "off" state (or very weakly fluorescent) in the absence of analyte because their fluorescence has been quenched by fluorescence resonance energy transfer. ${ }^{14}$ Once the analyte is added, the quencher status changes, and hence, the restoration of fluorescence of the fluorophore can be detected and used as an indicator to quantify the target analyte. Previous studies indicated that some nanohybrids can be used as turn-on fluorescence probes in AA determination, such as dumbbell-shaped carbon quantum dots/Au nanoclusters (NCs) and iron(III)-modulated nitrogen-doped graphene quantum dots. ${ }^{15,16}$ Meanwhile, Liu et al. $(2015)^{17}$ and Fong et al. $(2016)^{18}$ found graphene quantum dots and carbon dots (CDs) could also be used as fluorescence probes for turn-on sensing of AA. However, turn-off-on fluorescence models based on carbon nanocages (CNCs) have rarely been explored due to the difficulty of synthesis.

Recently, CNCs, as a class of nano-sized mesoporous carbon materials, have rapidly gained interest in the material science community due to their distinctive and well-defined structures, 
higher purity, unique chemical properties and suitable biocompatibility. ${ }^{18}$ To date, the methods for preparing CNCs include hard templating, soft templating and sacrificial templating approaches. ${ }^{19}$ However, all of these methods require expensive and dangerous chemical reagents, sophisticated equipment and trained professionals. As a result, it is highly desirable to prepare CNCs with a template-free method from common materials without a complicated chemical synthesis process. Carbon nanoparticles (CNPs) are found in various common foodstuffs, such as coffee, beverages and bakery products..$^{20-22}$ However, knowledge of the characteristics of CNCs derived from food, and their potential application in detection of bioactive substances, is still in its infancy.

Turbot fish (Scophthalmus maximus L.) is one of the most important commercial flatfish in Europe and Asia, with a global production of around $70000 \mathrm{t}$ per year, due to its high quality flesh. ${ }^{23}$ Grilled turbot is a popular delicacy with a characteristic roasted aroma. During grilling at elevated temperature, carbonaceous nanostructures can be produced via complicated reactions in grilled fish. ${ }^{22,24}$ In this study, we report the presence and characterization of fluorescent CNCs produced in grilled fish and their application as a "turn-on" sensor for AA detection. In the absence of AA, the fluorescence of the CNCs was quenched by $\mathrm{Fe}^{3+}$ due to the strong interaction between them. Upon reacting with $\mathrm{AA}, \mathrm{Fe}^{3+}$ was transformed to $\mathrm{Fe}^{2+}$ through the AA reduction effect, resulting in a "turn-on" fluorescent probe for sensitive and selective detection of AA. To demonstrate the practical application of this probe, the prepared probe was employed to test the AA content in vitamin $\mathrm{C}$ tablets. Compared to some existing methods, the developed turn-off-on method based on CNCs is highly economical, environmentally friendly, selective and sensitive to quantify AA.

\section{Material and methods}

\section{Materials}

Quinine sulfate, boric acid $\left(\mathrm{H}_{3} \mathrm{BO}_{3}\right)$, uric acid (UA) and sodium 2,6-dichloroindophenolate hydrate (DCPIP) were purchased from Aladdin Reagent Co. (Shanghai, China). Sephadex gel G-25 was purchased from Sigma-Aldrich Co. LLC (St. Louis, MO, USA). Ethanol absolute $\left(\mathrm{C}_{2} \mathrm{H}_{5} \mathrm{OH}\right)$, acetic acid $\left(\mathrm{CH}_{3} \mathrm{COOH}\right)$, phosphoric acid $\left(\mathrm{H}_{3} \mathrm{PO}_{4}\right)$ and chloroform $\left(\mathrm{CHCl}_{3}\right)$ were purchased from Kermel Chemical Reagent Co., Ltd. (Tianjin, China). Potassium chloride ( $\mathrm{KCl})$, lead chloride $\left(\mathrm{PbCl}_{2}\right)$, sodium chloride $(\mathrm{NaCl})$, calcium chloride $\left(\mathrm{CaCl}_{2}\right)$, cadmium chloride $\left(\mathrm{CdCl}_{2}\right)$, mercury(II) chloride $\left(\mathrm{HgCl}_{2}\right)$, zinc chloride $\left(\mathrm{ZnCl}_{2}\right)$, manganese sulfate monohydrate $\left(\mathrm{MnSO}_{4} \cdot \mathrm{H}_{2} \mathrm{O}\right)$, cupric chloride dehydrate $\left(\mathrm{CuCl}_{2} \cdot 2 \mathrm{H}_{2} \mathrm{O}\right)$, magnesium sulfate anhydrous $\left(\mathrm{MgSO}_{4}\right)$, cobalt nitrate hexahydrate $\left(\mathrm{Co}\left(\mathrm{NO}_{3}\right)_{2} \cdot 6 \mathrm{H}_{2} \mathrm{O}\right)$, iron(III) chloride $\left(\mathrm{FeCl}_{3}\right)$, and iron(II) chloride $\left(\mathrm{FeCl}_{2}\right)$ were purchased from Tianjin Damao Chemical Reagent Co., Ltd. (Tianjin, China). Ascorbic acid (AA), dopamine hydrochloride, human serum albumin (HSA), D-glucose and hemoglobin from bovine blood $(\mathrm{Hb})$ were purchased from Solarbio Co., Ltd. (Beijing, China). Vitamin C chewable tablets were purchased from Angle Co., Ltd. (Guangzhou, China). Ultrapure deionized water, used throughout the experiments, was prepared using a Milli-Q purification system (Millipore, USA).

\section{CNCs preparation}

Turbot fish (Scophthalmus maximus L.) was used for the CNCs' preparation in this study. Live turbot fish was purchased on the day of the experiment at a local fish market in Dalian, China. The fish was grilled in an electrical oven at $230{ }^{\circ} \mathrm{C}$ for $30 \mathrm{~min}$. Grilled flesh samples were mixed with ethanol $(100 \%)(\mathrm{w} / \mathrm{v}=1$ / 20) and vigorously stirred for 2 hours and filtered. Then the extracts were evaporated at $50{ }^{\circ} \mathrm{C}$ to remove the solvent, and dissolved in $80 \%$ chloroform and $20 \%$ ultrapure deionized water. The organic phase was removed by extraction and the aqueous solution was added to a Sephadex G-25 column. The fluorescent fractions were collected, lyophilized and stored in the dark at $-20{ }^{\circ} \mathrm{C}$ for further characterization and use. An extract from raw turbot was used as a control for fluorescence detection.

\section{Characteristics}

An electrical oven (SCC-WE-101, Self-Cooking Center 5 Senses) (Rational, Germany) was used for turbot grilling. Transmission electron microscopy (TEM) images were measured by using a JEM-2100 transmission electron microscope (JEOL, Tokyo, Japan). Absorption spectra were recorded by a Lambda 35 UVvis spectrophotometer (PerkinElmer, Waltham, MA, USA). Fluorescence spectra were collected on an F-2700 fluorescence spectrometer (Hitachi, Japan). The Fourier transform infrared spectroscopy (FTIR) spectra were measured on a Frontier FTIR spectrometer (PerkinElmer, Waltham, MA, USA). The timeresolved fluorescence decays were collected on a FluoroMax-4 spectrofluorometer (Horiba Scientific Co., Albany, NY, USA) with a $376 \mathrm{~nm}$ laser as the excitation source.

\section{Fluorescence "turn-off" by $\mathrm{Fe}^{3+}$}

Quenching by $\mathrm{Fe}^{3+}$ ions was performed at room temperature in $\mathrm{pH}$ 8.0 Britton-Robinson buffer (B-R buffer) containing $0.04 \mathrm{~mol} \mathrm{~L}^{-1} \mathrm{H}_{3} \mathrm{BO}_{3}, 0.04 \mathrm{~mol} \mathrm{~L}^{-1} \mathrm{H}_{3} \mathrm{PO}_{4}, 0.04 \mathrm{~mol} \mathrm{~L}^{-1} \mathrm{CH}_{3}$ $\mathrm{COOH}$ and $0.2 \mathrm{~mol} \mathrm{~L}^{-1} \mathrm{NaOH} .^{21}$ In a typical run, CNCs powder ( $5 \mathrm{mg} \mathrm{mL}^{-1}$ ) was added into B-R buffer, followed by the addition of different concentrations of $\mathrm{Fe}^{3+}$. After thorough mixing for $2 \mathrm{~min}$, the fluorescence intensity was recorded at an excitation wavelength of $330 \mathrm{~nm}$ and emission wavelength of $390 \mathrm{~nm} . F_{0}$ is the CNCs' fluorescence intensity before addition of $\mathrm{Fe}^{3+}$ ions. $F_{1}$ is the CNCs' fluorescence intensity after addition of $\mathrm{Fe}^{3+}$ ions. Then, the quenching efficiency $\left(F_{0}-F_{1}\right) / F_{0}$ was calculated.

\section{AA detection}

$5 \mathrm{mg} \mathrm{mL} \mathrm{m}^{-1}$ of CNCs were quenched by $100 \mu \mathrm{M} \mathrm{Fe}^{3+}$ in $\mathrm{B}-\mathrm{R}$ buffer ( $\mathrm{pH}$ 7.0) followed by adding AA at final concentrations of 0-20 $\mu \mathrm{M}$. After equilibration for $10 \mathrm{~min}$ at room temperature, $F_{2}$ (CNCs-Fe ${ }^{3+}$ fluorescence intensity after the addition of AA) was recorded with a fluorescence spectrometer using an excitation 
wavelength of $330 \mathrm{~nm}$ and emission wavelength of $390 \mathrm{~nm}$, and the fluorescence restoration $F_{2} / F_{1}$ was calculated.

\section{Analysis of AA tablets}

One gram of vitamin $\mathrm{C}$ chewable tablet containing $48 \mathrm{mg} \mathrm{AA}$ was dissolved in $50 \mathrm{~mL}$ of B-R buffer ( $\mathrm{pH}$ 7.0). The obtained AA solution was then diluted to $2.73,5.45,8.18,10.90 \mu \mathrm{M}$. The spiked samples were then incubated with the $\mathrm{CNCs}-\mathrm{Fe}^{3+}$ sensing solution for $10 \mathrm{~min}$ at room temperature, followed by fluorophotometry measurements at an excitation wavelength of $330 \mathrm{~nm}$ and emission wavelength of $390 \mathrm{~nm}$. For validation, the AA content of the tablet was compared to that measured by the commonly used method of DCPIP, as recommended by the Association of Official Analytical Chemists (AOAC).

\section{Statistical analyses}

All measurements in the study were done in triplicate. The results reported here were the means of the three trials. The results were expressed as means \pm standard deviation (SD). All the diagrams were plotted by Origin 9.2 software (Microcal, USA).

\section{Live subject statement}

Ethics approval for animal experimentation was obtained from the Animal Ethical Committee of Jiangsu University, Zhenjiang, China (SYXK/SU/2008-0024). All procedures were performed in accordance with the National Institutes of Health guidelines for the care and use of laboratory animals.

\section{Results and discussion}

\section{Extraction and characterization of CNCs}

The preparation of CNCs was extremely simple. It only involved the grilling of turbot flesh at $230{ }^{\circ} \mathrm{C}$ for $30 \mathrm{~min}$, without using any extra template, followed by solvent extraction and column chromatographic separation. The overall production yield of the CNCs was about $1.67 \%$ as calculated based on the weight of turbot flesh. The TEM images of hollow CNCs in Fig. 1 reveal that the outer diameter is in the range of $10-20 \mathrm{~nm}$ with a shell thickness of 3-5 $\mathrm{nm}$. The corresponding selected-area electron diffraction (SAED) pattern (inset of Fig. 1a) is similar to that of polycrystalline graphite, suggesting a well-crystallized structure. The high resolution TEM (HRTEM) image illustrates that the cage shell is composed of about 8 well-defined graphitic layers with a spacing of $0.33 \mathrm{~nm}$ (inset of Fig. 1b), which was attributed to the (100) diffraction plane of $\mathrm{sp}^{3}$ diamond-like carbon, similar to graphite. ${ }^{25}$ This kind of structure is similar to that previously obtained in the simultaneous synthesis of luminescent CNCs by laser ablation of carbon black suspension. ${ }^{26}$ The size distribution of the CNCs derived from carbon black ranged from 100 to $200 \mathrm{~nm}$, making them much larger than the CNCs from grilled turbot in this study. The formation of CNCs during the grilling of turbot may have resulted from heterogeneous self-assembly of structures and thermally induced polymerization of the product of spontaneous carbonization at high temperature, with extreme pyrolysis. ${ }^{27}$
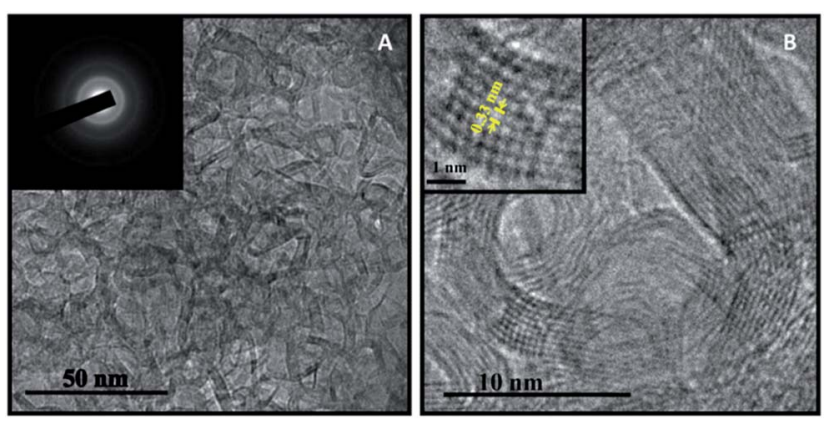

Fig. 1 (A) TEM images of CNCs from grilled turbot with selected-area electron diffraction (SAED) pattern (inset of (A)), and (B) high resolution TEM (HRTEM) image showing the cage shell composed of welldefined graphitic layers with a lattice spacing of $0.33 \mathrm{~nm}$ (inset of (B)).

Surface information of the functional groups on the CNCs was investigated by FTIR spectroscopy (Fig. S1†). The bending vibrations of the $\mathrm{C}-\mathrm{H}$ and $\mathrm{N}-\mathrm{H}$ groups were observed at 1046 $\mathrm{cm}^{-1}$. The symmetric stretching vibration band of $\mathrm{C}-\mathrm{O}-\mathrm{C}$ (1457 $\mathrm{cm}^{-1}$ ) indicates the existence of carboxylate groups on the CNCs' surface. The peak centered at $1665 \mathrm{~cm}^{-1}$ was due to the stretching vibrations of $\mathrm{C}=\mathrm{O}$ and $\mathrm{N}-\mathrm{H}$. The peak at $2925 \mathrm{~cm}^{-1}$ corresponded to the $\mathrm{C}-\mathrm{H}$ vibrations of methylene, and a broad absorption band at $3409 \mathrm{~cm}^{-1}$ was assigned to stretching vibrations of $\mathrm{O}-\mathrm{H}$ and $\mathrm{N}-\mathrm{H}$. These absorption bands indicate that the CNCs were surrounded by amino and hydroxyl groups, which gave them not only excellent water solubility but also feasible chelating capability with certain metal ions. ${ }^{28}$

The optical properties of the prepared CNCs are shown in Fig. 2. A small absorbance band at $320 \mathrm{~nm}$ can be found in the UV-vis spectrum of the CNCs in aqueous solution (black line, Fig. 2a), which can be assigned to the $n-\pi^{*}$ transition corresponding to the carbonyl/amine functional groups on the surface. ${ }^{29}$ The CNCs in aqueous solution exhibited bright blue emission under illumination by UV light at $365 \mathrm{~nm}$, which could be easily captured by a digital camera. A broad emission centered at $396 \mathrm{~nm}$ (blue line, Fig. 2a) was observed in the emission spectrum with an excitation wavelength at $330 \mathrm{~nm}$. The excitation spectrum (red line, Fig. 2a) reveals only one peak centered at $330 \mathrm{~nm}$, which indicates that the emission is related to one type of transition. It is necessary to mention that the raw turbot is non-emissive in the visible region under the same
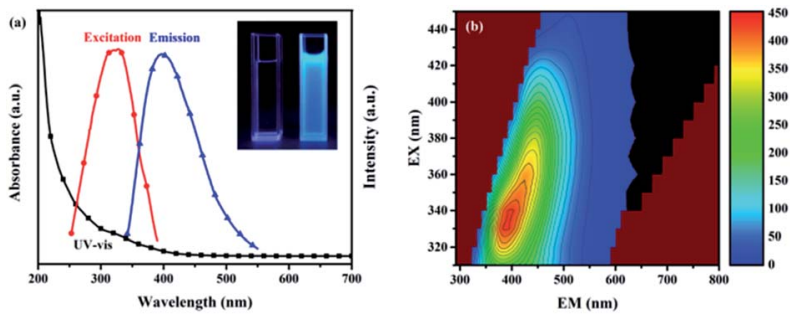

Fig. 2 (a) UV-vis absorption, excitation and emission spectrum of CNCs extracted from grilled turbot. (Inset) Photograph of the CNCs solution and water under excitation by UV light. (b) 2D fluorescence decay curves of CNCs extracted from grilled turbot. 
excitation wavelength of $330 \mathrm{~nm}$, confirming that the bright blue fluorescence originates from the CNCs generated during the high temperature grilling process. It is well known that the Maillard reaction is the most common reaction between reducing sugars and amino groups during the grilling of protein-rich food. The products of the Maillard reaction generally possess fluorescence. Therefore, the CNCs may be Maillard reaction products, and the chromophoric group may be a Schiff-base in conjugation with an electron donating group. The two-dimensional (2D) fluorescence spectra of the CNCs in Fig. $2 \mathrm{~b}$ show that the emission peak can be red-shifted by varying the excitation wavelength within 310-450 $\mathrm{nm}$. This excitation-dependent emission behavior provides a tunable emission property for CNCs in multicolor imaging. However, as the excitation wavelength increases, the emission intensity shows a decreasing trend. Moreover, the fluorescent quantum yield of the CNCs was measured to be about $16.37 \%$, which was calculated using quinine sulphate as the standard. The decay of fluorescence emission of the CNCs suspension was nonmonoexponential with an average lifetime of 6.82 ns $\left(\chi^{2}=\right.$ 1.022) (Fig. S2 $\dagger$ ). This result shows a similar photoluminescence property to the carbon quantum dots reported previously, which performed well as a real-time fluorescent assay for the detection of alkaline phosphatase activity. ${ }^{30}$

The fluorescent properties of the CNCs under various $\mathrm{pH}$ conditions were investigated. As shown in Fig. S3a, $\uparrow$ there is a certain degree of variability for the fluorescence intensity of the CNCs in $\mathrm{pH}$ 2.0-11.0 B-R buffers, with the maximum value obtained under neutral conditions. Under acidic and alkaline conditions, the imine form of the Schiff-base may be slightly disfavored, resulting in a decrease in fluorescence. In contrast to carbon dots derived from plant soot, ${ }^{31}$ the fluorescence intensity of the CNCs showed a $\mathrm{pH}$ independent property, which was consistent with the phenomenon reported in our previous work. ${ }^{21}$ Thus, this result demonstrates that the radiative recombination of the energy-trapping sites on the CNCs was hardly influenced by changing the $\mathrm{pH}$ value from alkaline to acidic, suggesting that the CNCs derived from the grilled turbot are applicable in a wide $\mathrm{pH}$ range. The fluorescent stability experiments of the CNCs (Fig. S3b†) indicated that the fluorescence intensity remained unchanged at room temperature for up to $48 \mathrm{~h}$. The high photostability will be beneficial for biological applications even after a long duration of incubation.

\section{Fluorescence "turn-off" by $\mathrm{Fe}^{3+}$}

Some Maillard reaction products are good chelators of metal ions. Since the CNCs produced during the grilling of turbot flesh are possibly Maillard reaction products, with good fluorescence, they have a good binding ability to metal ions. A range of metal ions, namely $\mathrm{K}^{+}, \mathrm{Na}^{+}, \mathrm{Ca}^{2+}, \mathrm{Pb}^{2+}, \mathrm{Cd}^{2+}, \mathrm{Hg}^{2+}, \mathrm{Zn}^{2+}$, $\mathrm{Mn}^{2+}, \mathrm{Cu}^{2+}, \mathrm{Mg}^{2+}, \mathrm{Co}^{2+}, \mathrm{Fe}^{3+}$ and $\mathrm{Fe}^{2+}$ (all at a final concentration of $110 \mu \mathrm{M}$ ), were chosen to assess the selectivity of the CNCs (Fig. S4 $\dagger$ ). It was found that the quenching efficiencies $\left(F_{0}\right.$ $\left.-F_{1}\right) / F_{0}$ were below $3 \%$ when adding $\mathrm{K}^{+}, \mathrm{Na}^{+}, \mathrm{Ca}^{2+}$, and $\mathrm{Pb}^{2+}$, i.e. those metals had negligible quenching effects on the CNCs. In contrast, $\mathrm{Cd}^{2+}, \mathrm{Hg}^{2+}, \mathrm{Zn}^{2+}, \mathrm{Mn}^{2+}, \mathrm{Cu}^{2+}, \mathrm{Mg}^{2+}, \mathrm{Co}^{2+}$, and $\mathrm{Fe}^{2+}$ exhibited moderate quenching effects. However, $\mathrm{Fe}^{3+}$ showed by far the highest fluorescence quenching efficiency against the CNCs, namely $85 \%$, indicating that the CNCs were selectively sensitive to $\mathrm{Fe}^{3+}$. A possible mechanism of fluorescence quenching of the CNCs by $\mathrm{Fe}^{3+}$ was hypothesized to be the nonradiative electron-transfer from the excited state of the CNCs to the d-orbital of $\mathrm{Fe}^{3+} \cdot{ }^{32}$ This quenching mechanism of $\mathrm{Fe}^{3+}$ was thoroughly discussed with respect to carbon dots derived from citric acid and ethylenediamine in previous work. ${ }^{33}$ In the present case, according to the FTIR results, many amino- and hydroxyl-containing functional groups appeared on the surface of the CNCs. These functional groups may have chelated $\mathrm{Fe}^{3+}$ to form complexes via coordination effects. These complexes may have changed the electronic state of the CNCs and affected the distribution of excitons, which may in turn have accelerated the nonradiative recombination of the excitons through effective photoelectron or energy transfer, thus resulting in the fluorescence quenching. ${ }^{34}$

The $\mathrm{pH}$ level is one of the critical parameters that affect the sensing ability of CNCs. As shown in Fig. S5a, $\uparrow$ the fluorescent quenching efficiency varied slightly with $\mathrm{pH}$ and was maximized at $\mathrm{pH}$ 8.0, suggesting $\mathrm{pH} 8.0$ is the optimal $\mathrm{pH}$ for the CNCs- $\mathrm{Fe}^{3+}$ sensor. This result indicates that the electrostatic repulsion between the protonated functional groups such as $\mathrm{N}-\mathrm{H}$ on the CNCs' surface and the $\mathrm{Fe}^{3+}$ ions was not significantly affected by the $\mathrm{pH}$ level. At $\mathrm{pH} 8.0$, the $\mathrm{N}-\mathrm{H}$ electron donor groups of the CNCs show maximum affinity to form a complex with $\mathrm{Fe}^{3+}$ through donating an electron pair, resulting in complete chelation of the $\mathrm{Fe}^{3+}$ content. ${ }^{35}$ In addition, the fluorescence response toward $100 \mu \mathrm{M} \mathrm{Fe}^{3+}$ at different reaction times from 2 to $20 \mathrm{~min}$ is displayed in Fig. S5b. $\uparrow$ Within the very short time of $2 \mathrm{~min}$, the CNCs were quenched significantly and their fluorescence response became stable, indicating a promising application of CNCs for fast sensing of $\mathrm{Fe}^{3+}$ through the "turn-off" effect.

Fig. 3a shows a three dimensional (3D) color surface map of the effect of the concentration of $\mathrm{Fe}^{3+}$ ions on the fluorescence intensities of the CNCs. The intensity of the maximum emission at $396 \mathrm{~nm}$ decreased gradually with increasing $\mathrm{Fe}^{3+}$ concentration, indicating that the CNCs' fluorescence was sensitive to $\mathrm{Fe}^{3+}$ concentration. Moreover, the quenching efficiency $\left(F_{0}-\right.$ $\left.F_{1}\right) / F_{0}$ of the CNCs was significantly correlated with the

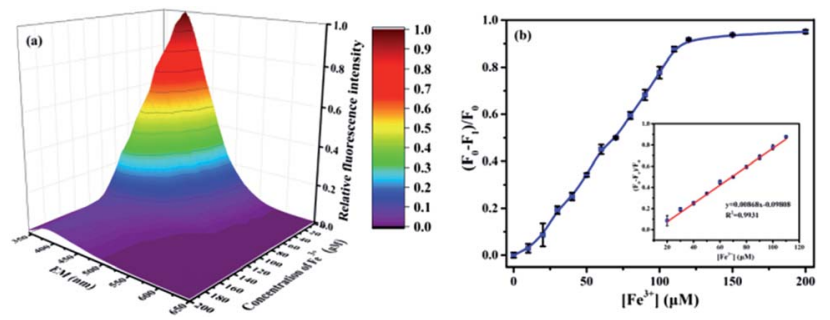

Fig. 3 (a) Fluorescence emission spectra in 3D color map surface image of CNCs obtained from grilled turbot after adding various concentrations of $\mathrm{Fe}^{3+}$ ions in the range of $0-200 \mu \mathrm{M}$. (b) Plots of the quenching efficiency $\left(F_{0}-F_{1}\right) / F_{0} v s$. the $\mathrm{Fe}^{3+}$ concentration. (Inset) $\left(F_{0}\right.$ $\left.-F_{1}\right) / F_{0} V s$. the $\mathrm{Fe}^{3+}$ concentration in the linear dynamic range. 
concentration of $\mathrm{Fe}^{3+}$ in the range $20-110 \mu \mathrm{M}$ (Fig. 3b). The linear regression equation is $y=0.00868 x-0.0981$ with a correlation coefficient of 0.993 . The detection limit (DL) of the CNCs for $\mathrm{Fe}^{3+}$, calculated from the equation $\mathrm{DL}=\left(3 \times S_{\mathrm{b} 1}\right) / S$, was $3.96 \mu \mathrm{M}$, where $S_{\mathrm{b} 1}$ is the standard deviation of the blank solution; $S$ is the slope of the calibration curve. ${ }^{35}$ Upon adding $110 \mu \mathrm{M}$ of $\mathrm{Fe}^{3+}$, the quenching efficiency reached a plateau stage. Therefore, $110 \mu \mathrm{M}$ was chosen to be the optimal concentration of $\mathrm{Fe}^{3+}$ to turn-off the CNCs for the following detection of AA. In comparison with Fong's and Gu's systems, our work required a lower concentration of quenchers for quenching fluorescence, suggesting an improved quenching efficiency. ${ }^{18,36}$

\section{Fluorescence "turn-on" by AA}

The possible mechanism of fluorescence quenching of the CNCs by $\mathrm{Fe}^{3+}$ was analyzed from the point of view of their ion selective chemical structure and charge/energy transfer effect. The hydroxyl groups of the CNCs could react with $\mathrm{Fe}^{3+}$ and form coordination complexes. $^{34}$ It is also well known that AA is a strong reducing agent which is stabilized by electron delocalization and exists in mono-anionic form $\left(\mathrm{AH}^{-}\right) .{ }^{37}$ Therefore, it can easily attack the positively charged $\mathrm{Fe}^{3+}$ and reduce the oxidation state of the cations from $\mathrm{Fe}^{3+}$ to $\mathrm{Fe}^{2+}$. As a result, the complexation between $\mathrm{Fe}^{3+}$ and the CNCs will be disrupted, leading to the recovery of the CNCs' fluorescence. In other words, the fluorescence of the CNCs quenched by $\mathrm{Fe}^{3+}$ can be "turned on" again upon the addition of AA. More specifically, the "turn-off-on" mechanism of the CNCs- $\mathrm{Fe}^{3+}$ complexes for quantitative detection of AA is elaborated in scheme 1. The fluorescence of the CNCs is quenched upon forming the CNCs$\mathrm{Fe}^{3+}$ complexes due to the quenching effect of the $\mathrm{Fe}^{3+}$, while the fluorescence signal will recover upon the addition of AA, which can reduce the $\mathrm{Fe}^{3+}$ to $\mathrm{Fe}^{2+}$ ions. As described above, $\mathrm{Fe}^{2+}$ has a relatively weak quenching effect on the CNCs, and the fluorescence intensity increases along with the addition of AA. In view of this phenomenon, a facile, sensitive sensing method

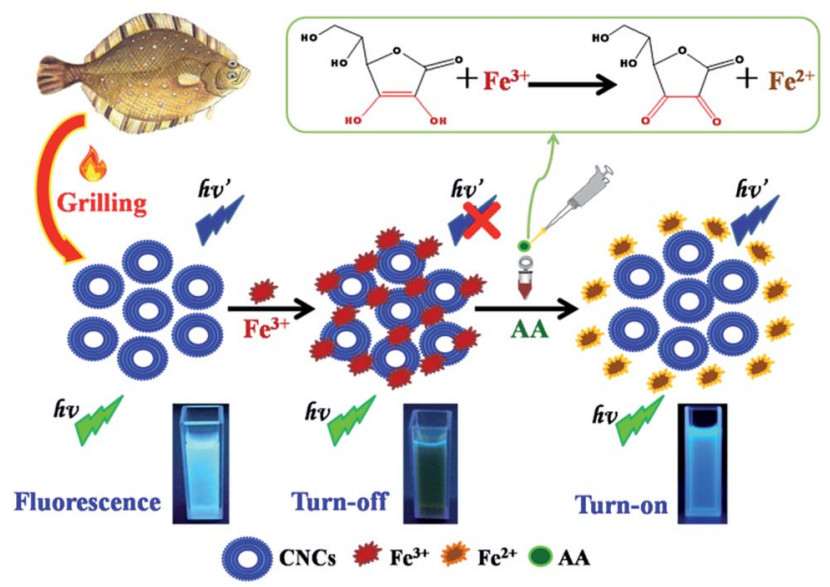

Scheme 1 The "turn-off-on" mechanism of CNCs fluorescent probe for detection of AA. through measuring the fluorescence change of the CNCs can be developed for the detection of AA.

To investigate the $\mathrm{pH}$ effect on the fluorescence intensity of the CNCs probe, B- $\mathrm{R}$ buffer solutions in the range of $\mathrm{pH}$ 2.011.0 were used for comparative experiments under the same conditions. As shown in Fig. S6a, $\uparrow$ the fluorescence restoration $F_{2} / F_{1}$ of CNCs- $\mathrm{Fe}^{3+}$ increased as the $\mathrm{pH}$ increased from 2.0 to 6.0, and the maximum value was observed at $\mathrm{pH}$ 7.0. When the $\mathrm{pH}$ changed from 7.0 to 11.0 , the fluorescence restoration $F_{2} / F_{1}$ showed a slight drop. The possible reason is as follows: the $\mathrm{p} K_{\mathrm{a}}$ value of $\mathrm{AA}$ is about 4.25, and the concentration of $\mathrm{AH}^{-}$is higher than that of the protonated form $\left(\mathrm{AH}_{2}\right)$ at high $\mathrm{pH}$ values such as $7.4 .^{38}$ Thus, the more $\mathrm{AH}^{-}$is present, the more $\mathrm{Fe}^{3+}$ ions are converted to $\mathrm{Fe}^{2+}$. Therefore, the fluorescence restoration $F_{2} /$ $F_{1}$ at the neutral condition $(\mathrm{pH}=7.0)$ was selected in the subsequent detection. Moreover, the AA-induced disintegration of CNCs- $\mathrm{Fe}^{3+}$ aggregates may take time to reach completion. The time evolution of the fluorescence restoration $F_{2} / F_{1}$ of CNCs- $\mathrm{Fe}^{3+}$ upon the addition of AA was also investigated. Fig. S6(b) $\dagger$ shows that the fluorescence restoration $F_{2} / F_{1}$ of the CNCs was fully restored and reached its maximum value within $10 \mathrm{~min}$ of the addition of AA (at a concentration of $10 \mu \mathrm{M}$ ). The free CNCs were very stable and no detectable changes were observed for the fluorescence restoration $F_{2} / F_{1}$ after $10 \mathrm{~min}$. These results implied that quantification of AA can be performed in a simple mix-and-detect manner. Therefore, $10 \mathrm{~min}$ was chosen as the reaction time in subsequent experiments.

For AA detection, the fluorescence restoration $F_{2} / F_{1}$ of CNCs$\mathrm{Fe}^{3+}$ induced by different concentrations of $\mathrm{AA}$ is shown in Fig. 4. Firstly, the fluorescence emission spectra in 3D surface color map for the $\mathrm{CNCs}-\mathrm{Fe}^{3+}$ were measured to investigate the fluorescence behavior changes (Fig. 4a). The fluorescence intensity of the $\mathrm{CNCs}-\mathrm{Fe}^{3+}$ at $390 \mathrm{~nm}$ increased significantly when $2 \mu \mathrm{M}$ of AA was added, and it continuously increased until reaching its maximum value after adding $20 \mu \mathrm{M}$ of AA. Thus, the recovery of the fluorescence signal can be intuitively observed from the $3 \mathrm{D}$ color map surface image. Secondly, the quantitative fluorescence restoration $\left(F_{2} / F_{1}\right)$ of $\mathrm{CNCs}-\mathrm{Fe}^{3+}$ in Fig. $4 \mathrm{~b}$ shows a dose-dependent behavior upon the addition of AA. The inset of Fig. $4 \mathrm{~b}$ represents the calibration curve of AA, which shows good response linearity between the fluorescence restoration $F_{2} /$ $F_{1}$ and the concentration of AA in the dynamic range from 2 to
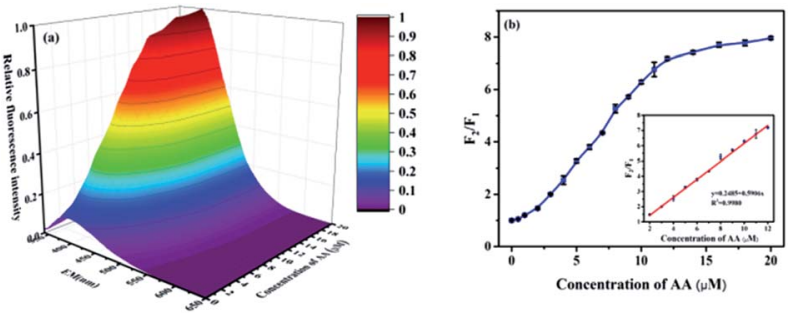

Fig. 4 (a) Fluorescence emission spectra of $\mathrm{CNCs}-\mathrm{Fe}^{3+}$ after adding various concentrations of $A A$ in the range of $0-20 \mu \mathrm{M}$, EM: emission wavelength, (b) plots of the fluorescence restoration $F_{2} / F_{1}$ (at $390 \mathrm{~nm}$ ) $v s$. the AA concentrations. (Inset) $F_{2} / F_{1} v s$. the AA concentrations in the range of $2-12 \mu \mathrm{M}$ in the linear dynamic range. 
Table 1 Comparison of the present approach with other reported methods for the detection of AA

\begin{tabular}{|c|c|c|c|c|}
\hline Methods & Probe & Detection range & Detection limit & References \\
\hline This work & CNCs & $2-12 \mu \mathrm{M}$ & $97.2 \mathrm{nM}$ & \\
\hline HPLC & & $0.5-8.0 \mathrm{~g} \mathrm{~mL}^{-1}(2.84-4.54 \mathrm{mM})$ & $0.27 \mathrm{~g} \mathrm{~mL}^{-1}(1.53 \mathrm{mM})$ & 10 \\
\hline Electrochemical method & $\mathrm{Ni}(\mathrm{OH})_{2}$ nanoboxes & $10-200 \mu \mathrm{M}$ & $3 \mu \mathrm{M}$ & 8 \\
\hline Fluorescence spectroscopy & $\begin{array}{l}\text { Dumbbell-shaped carbon } \\
\text { quantum dots/AuNCs }\end{array}$ & $0.15-15 \mu \mathrm{M}$ & $0.105 \mu \mathrm{M}$ & 17 \\
\hline Fluorescence spectroscopy & Graphitic carbon nitride & $0.6-300 \mu \mathrm{M}$ & $0.15 \mu \mathrm{M}$ & 37 \\
\hline
\end{tabular}

Table 2 AA detection in real samples in this work and by DCPIP method ${ }^{b}$

\begin{tabular}{|c|c|c|c|c|c|c|}
\hline $\begin{array}{l}\text { Real samples } \\
\text { Add }(\mu \mathrm{M})\end{array}$ & Found $(\mu \mathrm{M})$ & $\operatorname{RSD},(\%)(n=6)^{a}$ & Recovery (\%) & Found $(\mu \mathrm{M})$ & $(\%)(n=6)^{a}$ & Recovery (\%) \\
\hline 5.45 & 6.01 & 4.63 & 110.23 & 5.60 & 4.96 & 102.67 \\
\hline 8.18 & 9.10 & 40.85 & 111.27 & 8.45 & 1.54 & 104.76 \\
\hline 10.90 & 11.85 & 20.32 & 108.67 & 11.35 & 5.56 & 103.32 \\
\hline
\end{tabular}

$12 \mu \mathrm{M}$. The regression equation is $y=0.2485+0.5906 x$, where $y$ and $x$ denote the fluorescence recovery factor $F_{2} / F_{1}$ and the AA concentration, respectively. The correlation coefficient of the calibration curve is 0.998 . Considering the reported methods listed in Table 1 , the detection range in this work is most closely comparable to those of the dumbbell-shaped carbon quantum dots/AuNCs $(0.15-15 \mu \mathrm{M})^{17}$ and graphene quantum dots $(0.3-10$ $\mu \mathrm{M}) .{ }^{19}$ However, due to the good reproducibility, the detection limit of AA in this work was as low as $79.2 \mathrm{nM}$, calculated as the concentration corresponding to 3 standard deviations of the background signal. This detection limit is not only far below that obtained by HPLC, ${ }^{\mathbf{1 0}}$ flame atomic absorption spectrometry $^{11}$ and the electrochemical method, ${ }^{8}$ but also less than other forms of fluorescence spectroscopy. ${ }^{15,17,37}$ Therefore, this method based on using $\mathrm{CNCs}-\mathrm{Fe}^{3+}$ as a probe has high sensitivity, a very low detection limit and excellent precision for quantitative detection of AA.

The selectivity of the $\mathrm{CNCs}-\mathrm{Fe}^{3+}$ for the detection of AA was explored in the presence of other possible reducing agents. As shown in Fig. S7, $\dagger$ only AA induced a significant fluorescence restoration $\left(F_{2} / F_{1}\right)$ of $\mathrm{CNCs}-\mathrm{Fe}^{3+}$, about 5 -fold greater as compared with other reducing agents. In comparison with the control, no noticeable fluorescence restoration $\left(F_{2} / F_{1}\right)$ was observed after the interaction of CNCs- $\mathrm{Fe}^{3+}$ with $\mathrm{UA}$, dopamine, HSA, D-glucose or $\mathrm{Hb}$. Although these alternative reducing agents had some reducing power, being able to partially restore the fluorescence of $\mathrm{CNCs}-\mathrm{Fe}^{3+}$, the resulting fluorescence signals were lower than that of CNCs- $\mathrm{Fe}^{3+}$ in the presence of AA. Therefore, the CNCs- $\mathrm{Fe}^{3+}$ sensor possesses excellent selectivity and reliability toward AA quantification.

\section{Application of CNCs probe for detection of AA in real samples}

For the real sample assay, the prepared CNCs probe was applied for the detection of AA in a vitamin $\mathrm{C}$ chewable tablet of the brand Angle $\AA$, which can be purchased from ordinary pharmacies. Four different concentrations of vitamin $\mathrm{C}$ chewable tablets were chosen as representative samples. The common method of DCPIP titration, recommended by the AOAC, was used as a control for comparison. The results obtained by the two methods are shown in Table 2. It can be noted that the recovery values of the DCPIP method are within the range of 108.67-111.27\% with a relative standard deviation (RSD) of $\sim 22 \%$, and the corresponding results for the CNCs probe are $99.77-104.76 \%$ with a lower RSD of less than $6 \%$. This result is similar to that obtained in Fong's work, which used carbon dots as a sensing probe to detect vitamin $\mathrm{C}$ soluble tablets with close to $100 \%$ recovery. ${ }^{18}$ The results demonstrated that negligible interference was found in the determination of $\mathrm{AA}$ in real samples. As such, the CNCs derived from grilled turbot flesh might have potential as novel nano-sized materials in fast detecting of AA in real samples.

\section{Conclusions}

In summary, a fluorescent sensor based on a bright fluorescent CNCs- $\mathrm{Fe}^{3+}$ system derived from grilled turbot has been developed for fast "turn-off-on" detecting of AA. The structural characterization revealed that the food-originated CNCs have an outer diameter of 10-20 nm with a shell thickness of 3-5 nm. By using an $\mathrm{Fe}^{3+}$ quenching strategy, with fluorescence recovery upon addition of $\mathrm{AA}$, the detection limit was determined as $97.2 \mathrm{nM}$ with a linear response range of 2.0 to $12 \mu \mathrm{M}$. 
Additionally, this efficient fluorescence probe was successfully applied to the quantitative detection of AA in real samples. This approach based on CNCs may provide new insights into the recognition of bioactive substances like ascorbic acid in real samples.

\section{Acknowledgements}

This work was supported by National Key Research and Development Project (2016YFD0400404) and the National Nature Science Foundation of China (31601389). The authors would like to thank Professor Tong Wang for her critical reading of the manuscript.

\section{Notes and references}

1 A. A. Ensafi, M. Taei and T. Khayamian, J. Electroanal. Chem., 2009, 633, 212-220.

2 T. R. L. C. Paixão and M. Bertotti, J. Pharm. Biomed. Anal., 2008, 46, 528-533.

3 S. M. Chen, J. Y. Chen and V. S. Vasantha, Electrochim. Acta, 2006, 52, 455-465.

4 T. Dimitrijević, P. Vulić, D. Manojlović, A. S. Nikolić and D. M. Stanković, Anal. Biochem., 2016, 504, 20-26.

5 P. J. O'Connell, C. Gormally, M. Pravda and G. G. Guilbault, Anal. Chim. Acta, 2001, 431, 239-247.

6 R. B. Gómez, S. Roux, F. Courtois and C. Bonazzi, Food Chem., 2016, 211, 583-589.

7 Y. Zhang, L. Z. Pei, T. Wei and N. Lin, J. Bionanosci., 2016, 10, 134-139.

8 D. Chen, Y. Cao, Y. Chen, W. Huang, B. Wang, X. Wang and J. Tu, RSC Adv., 2016, 6, 43598-43604.

9 R. Benlloch, R. Farré and A. Frigola, J. Liq. Chromatogr., 2006, 16, 3113-3122.

10 G. Burini, J. Chromatogr. A, 2007, 1154, 97-102.

11 M. C. Yebra, R. M. Cespón and A. Moreno-Cid, Anal. Chim. Acta, 2001, 448, 157-164.

12 Z. Q. Zhang and Y. C. Jiang, At. Spectrosc., 2000, 21, 100104.

13 H. Huang, B. Wang, M. Chen, M. Liu, Y. Leng, X. Liu, Y. Li and Z. Liu, Sens. Actuators, B, 2016, 235, 356-361.

14 C. Yang, W. Xiu, S. Lei, W. Deng, H. Liu, S. Ge, Y. Mei and X. Song, Biosens. Bioelectron., 2016, 80, 17-23.

15 W.-J. Niu, D. Shan, R.-H. Zhu, S.-Y. Deng, S. Cosnier and X.-J. Zhang, Carbon, 2016, 96, 1034-1042.

16 X. Kong, Y. Gong and Z. Fan, J. Fluoresc., 2016, 1-8.
17 J.-J. Liu, Z.-T. Chen, D.-S. Tang, Y.-B. Wang, L.-T. Kang and J.-N. Yao, Sens. Actuators, B, 2015, 212, 214-219.

18 J. F. Y. Fong, S. F. Chin and S. M. Ng, Biosens. Bioelectron., 2016, 85, 844-852.

19 X. W. Lou, L. A. Archer and Z. Yang, Adv. Mater., 2008, 20, 3987-4019.

20 H. Liao, C. Jiang, W. Liu, J. M. Vera, O. D. Seni, K. Demera, C. Yu and M. Tan, J. Agric. Food Chem., 2015, 63, 8527-8533.

21 C. Jiang, H. Wu, X. Song, X. Ma, J. Wang and M. Tan, Talanta, 2014, 127, 68-74.

22 A. M. Al-Hadi, V. S. Periasamy, J. Athinarayanan and A. A. Alshatwi, Environ. Toxicol. Pharmacol., 2015, 41, 103112.

23 M. Gu, N. Bai, Y. Zhang and Å. Krogdahl, Aquaculture, 2016, 464, 286-295.

24 H. M. Bolt, R. Marchan and J. G. Hengstler, Arch. Toxicol., 2012, 86, 1629-1635.

25 X. T. Zheng, A. Ananthanarayanan, K. Q. Luo and P. Chen, Small, 2015, 11, 1620-1636.

26 S. Hu, J. Mater. Chem. C, 2012, 22, 1957-1961.

27 A. M. Al-Hadi, V. S. Periasamy, J. Athinarayanan and A. A. Alshatwi, Environ. Toxicol. Pharmacol., 2015, 41, 103112.

28 A. Barati, M. Shamsipur, E. Arkan, L. Hosseinzadeh and H. Abdollahi, Mater. Sci. Eng., C, 2015, 47, 325-332.

29 L. I. Ting, J. Tang, F. Fang, D. Fang, X. Fang, X. Chu, L. I. Jinhua, F. Wang, X. Wang and Z. Wei, J. Mater. Chem. C, 2014, 2, 6921-6939.

30 S. Q. Zhao, J. C. Lu, Y. H. Yuan, T. Cong, J. S. Jia, R. C. Jian and F. Hui, Biosens. Bioelectron., 2015, 68, 675-680.

31 M. Tan, L. Zhang, R. Tang, X. Song, Y. Li, H. Wu, Y. Wang, G. Lv, W. Liu and X. Ma, Talanta, 2013, 115, 950-956.

32 Y. L. Zhang, L. Wang, H. C. Zhang, Y. Liu, H. Y. Wang, Z. H. Kang and S. T. Lee, RSC Adv., 2013, 3, 3733-3738.

33 Y. Song, S. Zhu, S. Xiang, X. Zhao, J. Zhang, H. Zhang, Y. Fu and B. Yang, Nanoscale, 2014, 6, 4676-4682.

34 C. Han, W. Ru, K. Wang, H. Xu, M. Sui, J. Li and X. Kai, Biosens. Bioelectron., 2016, 83, 229-236.

35 G. Gedda, C. Y. Lee, Y. C. Lin and H. F. Wu, Sens. Actuators, B, 2015, 224, 396-403.

36 J. Gu, D. Hu, W. Wang, Q. Zhang, M. Zhen, X. Jia and X. Kai, Biosens. Bioelectron., 2015, 68, 27-33.

37 M. Rong, L. Lin, X. Song, Y. Wang, Y. Zhong, J. Yan, Y. Feng, X. Zeng and C. Xi, Biosens. Bioelectron., 2015, 68, 210-217.

38 I. Ahmad, K. Qadeer, A. Hafeez, S. Zahid, M. A. Sheraz and S. U. R. Khattak, AAPS PharmSciTech, 2014, 15, 1324-1333. 